\section{Available online at www.sciencedirect.com science@Direct.}

Journal of Hydrology 297 (2004) 285-300

\section{Journal \\ of \\ Hydrology}

www.elsevier.com/locate/jhydrol

\title{
Groundwater influences on soil moisture and surface evaporation ${ }^{\text {}}$
}

\author{
Xi Chen ${ }^{1}$, Qi Hu* \\ Climate and Bio-Atmospheric Sciences Group, School of Natural Resource Sciences, University of Nebraska-Lincoln, \\ 237 L.W. Chase Hall, Lincoln, NE 68583-0728, USA
}

Received 11 September 2003; revised 6 April 2004; accepted 16 April 2004

\begin{abstract}
Soil hydrological processes play an important role in land-atmosphere system. In most climate models, these processes are described by soil moisture variations in the first $2 \mathrm{~m}$ of soil resulting from precipitation, evaporation, and transpiration. Groundwater effects on soil moisture variations and surface evaporation are either neglected or not explicitly treated. Although groundwater may have a small effect on soil moisture in areas with a deep groundwater table, groundwater can act as a soil water source and have substantial effects in areas where the water table is near or within a model's soil column. How groundwater affects soil moisture, its vertical distribution, as well as the surface water flux are the issues addressed in this study.

A soil hydrological model was developed to include groundwater effects by allowing water exchange between the unsaturated zone and groundwater. The model uses a vertically varying saturation hydraulic conductivity, and is evaluated using observations at one station in the Nebraska Sand Hills. Model results show its ability to describe the roles of groundwater in maintaining the observed soil moisture, especially in deep layers. In addition, comparisons show that the soil moisture content in the first meter of the soil column from the model with groundwater is $21 \%$ greater than that from a model without groundwater. High soil moisture content in the root zone results in increased evapotranspiration (ET). The average ET in three periods from 1998 to 2000 is $7-21 \%$ higher when groundwater is considered in the model. Because of the groundwater effects, spatial variations in the groundwater table can create an additional spatial variability of soil moisture and surface water flux. This additional variability could be important in development of storms in regions whose domain has a large portion with high groundwater table.
\end{abstract}

(C) 2004 Elsevier B.V. All rights reserved.

Keywords: Groundwater; Soil moisture; Surface evaporation; Model; Nebraska Sand Hills

\section{Introduction}

Temporal and spatial variations of soil moisture are receiving increased attention in climate studies

\footnotetext{
Agricultural Research Division, University of NebraskaLincoln Contribution Number 15988.

* Corresponding author. Tel.: + 1-402-472-6642; fax: + 1-402472-6614.

E-mail address: qhu2@unl.edu (Q. Hu).

1 Present address: Laboratory of Water Resources Development, Hehai University, Nanjing, China.
}

because soil moisture is an essential element in processes that drive land surface water and energy fluxes, which affect ecosystem dynamics and biogeochemical cycles in the land-atmosphere system. Soil moisture in the unsaturated zone changes as a result of precipitation recharge and water exchange with both the atmosphere and groundwater. Most studies of water exchange between the unsaturated zone and the atmosphere have focused on understanding soil moisture variations and their effects on atmospheric boundary layer processes affecting weather 
and climate (e.g. Manabe, 1969; Ookouchi et al., 1984; Dickinson, 1984; Pielke and Avissar, 1990; Pielke et al., 1991). In those studies, groundwater effects on soil moisture variation have been neglected, however.

In the mean time, several land surface and soil hydrological models (LSM) have been developed and used in mesoscale atmospheric models and general circulation models (GCM). Some of those LSM have sophisticated vertical exchange processes of moisture as well as temperature between the soil, the biosphere, and the atmosphere (Dickinson, 1984; Dickinson et al., 1986; Sellers et al., 1986; Pan and Mahrt, 1987; Xue et al., 1991; Chen and Dudhia, 2001), while others use simplified representations of vertical exchange physics that incorporate the effects of spatial heterogeneity in topography, soil, and vegetation on soil moisture variation and related hydrological processes (e.g. Entekhabi and Eagleson, 1989; Famiglietti and Wood, 1990, 1994; Wood et al., 1992; Schaake et al., 1996; Stieglitz et al., 1997; Koster et al., 2000). In most of the LSM, the soil column is divided into number of layers to describe, in various degrees and in different ways, vertical soil moisture exchange processes, such as infiltration and percolation, surface and underground runoff, and effect of the root density profile on soil moisture (Acs, 1994). These layers comprise a root zone, usually $1 \mathrm{~m}$ thick, and a deep soil zone beneath it. The thickness of the layer beneath the root zone varies; it is $1 \mathrm{~m}$ in the OSU model (Pan and Mahrt, 1987) and the LSM used in the Penn State-NCAR MM5 (Chen and Dudhia, 2001). It varies between 1 and $2 \mathrm{~m}$ in the SSiB model (Xue et al., 1991), and is fixed at $10 \mathrm{~m}$ in the BATS scheme (Dickinson et al., 1986). Many of these LSM, particularly the ones based on the TOPMODEL (Beven and Kirkby, 1979), are focused on the effects of spatial heterogeneity of soil moisture on the surface hydrology and the atmosphere (e.g. Entekhabi and Eagleson, 1989; Famiglietti and Wood, 1994; Stieglitz et al., 1997; Koster et al., 2000). These models employ vertical layers that extend to the depth of the groundwater table and do, in fact, account for the impact of distribution of the groundwater table on spatial heterogeneity of soil moisture in the upper layers. However, few of these models explicitly account for the effects of groundwater on soil moisture and surface evaporation. Other LSM, which extend over greater vertical depths, treat the deepest soil layer only by permitting gravity drainage across the layer's lower boundary. They do not permit groundwater input to the deepest layer of the model soil column.

In many shallow groundwater regions, such as wetlands and lowlands in river valleys, a high groundwater table and significant hydraulic gradients between the saturated zone and the root zone lead to continuous supply of groundwater to the root zone. In those regions, the role of groundwater in variations of the root zone soil moisture becomes essential. One area where groundwater serves as a major source of soil moisture is the Sand Hills in west-central Nebraska. The Sand Hills $\left(\sim 50,000 \mathrm{~km}^{2}\right)$ have a thick surface layer of fine sand. Through this sandy layer, soil water percolates to the groundwater at a speed as fast as $3.4 \mathrm{~m} \mathrm{day}^{-1}$ (Bleed, 1998), leaving little time for evaporation to consume the soil water. This unique geological setting helps create a large groundwater reserve in the area: the Ogallala aquifer. In the Sand Hills, groundwater effects determine the variation of soil moisture as well as surface evaporation and streamflow (Bleed, 1998; Bentall, 1998). Indeed, areas with such significant groundwater effects on the soil moisture and surface water comprise a relatively small fraction of the entire land surface. Yet the groundwater table distribution in those areas creates an additional spatial heterogeneity, similar to that created by variations in topography, surface vegetation, and soil properties, and are critically important for regional processes influencing spatial variations of soil moisture, evapotranspiration (ET), and precipitation and floods (Wood et al., 1992).

The lack of understanding of the effect of groundwater on soil moisture prompted this study. In this paper, we evaluate and describe the influence of groundwater on root zone soil moisture using both observational data and modeling analysis. A soil hydrological model that includes the groundwater effect on soil moisture is described in the next section. In addition to including groundwater, this model uses a vertically varying saturated soil hydraulic conductivity, as suggested in Beven (1984) and Elsenbeer et al. (1992), to consider the decrease of soil permeability with depth. In Section 3, effects on groundwater in two extremely dry and wet weather scenarios are presented. In Section 3.2.1, the model is validated using observations, including groundwater 
table variation, at Gudmundsen in the Nebraska Sand Hills, and is then used to describe soil moisture variations and how they are affected by groundwater. The model data are further used to analyze the effects of groundwater on local water cycle. Groundwater effects at a small regional scale are examined in Section 4. Results show that spatial variations of the groundwater table and groundwater effects on soil moisture can more accurately describe the total surface moisture flux in the area, suggesting the importance of including groundwater in LSM to improve description of regional water cycles. A summary is given in Section 5.

\section{A soil hydrological model}

The structure of the soil hydrological model used in this study is shown in Fig. 1. The model has a surface layer of vegetation canopy and four soil layers. The thicknesses of the soil layers from shallow to deep soil were specified as $0.1,0.15,0.25$, and $0.5 \mathrm{~m}$. The soil column contains a root zone whose moisture variation is influenced by groundwater. The sources of soil water are precipitation and groundwater. In vegetated areas, a portion of the precipitation is intercepted by the canopy, and the rest falls to the ground and infiltrates into the soil and further percolates down to deeper soil layers. Some of the water eventually reaches the saturated zone to recharge the groundwater. Concurrently with these recharging processes, evaporation and transpiration are taking place at the canopy and the ground surface, resulting in soil water loss.

Soil moisture variation in the model is described by the Richard's equation:

$\frac{\partial \theta}{\partial t}=\frac{\partial}{\partial z}\left(D \frac{\partial \theta}{\partial z}\right)+\frac{\partial K}{\partial z}+F(t, \theta)$

where $\theta$ is soil moisture content in $\mathrm{m}^{3} \mathrm{~m}^{-3}, t$ is time, $z$ the vertical coordinate, $F(t, \theta)$ the source and sink term accounting for precipitation, evaporation, and surface runoff, $K$ the unsaturated hydraulic conductivity, and $D$ the soil water diffusivity. Both $K$ and $D$ are functions of $\theta$ and are computed from $K(\theta)=$ $K_{\mathrm{s}}\left(\theta / \theta_{\mathrm{s}}\right)^{2 b+3}$ and $D(\theta)=K(\theta)(\partial \Psi / \partial \theta)$, where $\Psi$ is soil water tension function and $\Psi(\theta)=\Psi_{\mathrm{s}} /\left(\theta / \theta_{\mathrm{s}}\right)^{b}$ in which $b$ is a curve-fitting parameter. In these expressions, $K_{\mathrm{s}}, \Psi_{\mathrm{s}}$, and $b$ are functions of soil types following Cosby et al. (1984). Both $K$ and $D$ are highly non-linear functions of soil moisture.

Integrating Eq. (1) through the soil layers under the assumption of vertically homogeneous soil hydraulic properties within each layer yields

$d_{1} \frac{\partial \theta_{1}}{\partial t}=-D\left(\frac{\partial \theta}{\partial z}\right)_{1}-K_{1}+P_{\mathrm{d}}-R-E_{\mathrm{dir}}-E_{\mathrm{T} 1}$,

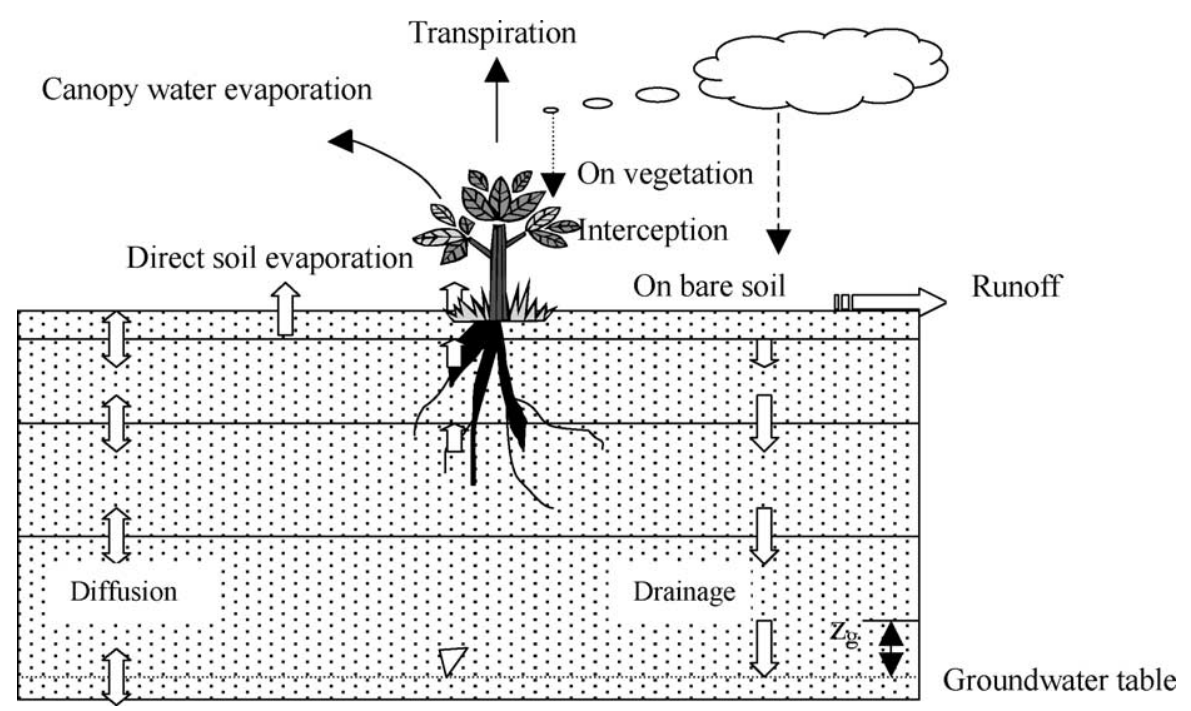

Fig. 1. A schematic of the multiplayer soil hydrological model. 
$d_{2} \frac{\partial \theta_{2}}{\partial t}=D\left(\frac{\partial \theta}{\partial z}\right)_{1}-D\left(\frac{\partial \theta}{\partial z}\right)_{2}+K_{1}-K_{2}-E_{\mathrm{T} 2}$,

$d_{3} \frac{\partial \theta_{3}}{\partial t}=D\left(\frac{\partial \theta}{\partial z}\right)_{2}-D\left(\frac{\partial \theta}{\partial z}\right)_{3}+K_{2}-K_{3}-E_{\mathrm{T} 3}$,

and

$d_{4} \frac{\partial \theta_{4}}{\partial t}=D\left(\frac{\partial \theta}{\partial z}\right)_{3}+K_{3}-K_{4}$

In the above, the subscript, $i=1,2,3$, and 4 , is the soil layer index (see Fig. 1), $d_{i}$ the thickness of $i$ th soil layer, $P_{\mathrm{d}}$ the precipitation falling on the ground, $R$ the surface runoff, $K_{i}$ the vertical unsaturated soil hydraulic conductivity. In Eq. (5) $K_{4}$ is the gravitational percolation or subsurface runoff, and in Eq. (2), $E_{\text {dir }}$ is the evaporation from the top soil surface, and $E_{\mathrm{T} i}$ in Eqs. (2)-(4) are the transpiration by vegetation through roots. A simple linear method (Mahfouf and Noilhan, 1991)

$E_{\mathrm{dir}}=\left(1-\sigma_{\mathrm{f}}\right) \beta E_{\mathrm{p}}$

is used to calculate $E_{\mathrm{dir}}$, where $\beta=\left(\theta_{1}-\theta_{\mathrm{w}}\right) /\left(\theta_{\text {ref }}-\theta_{\mathrm{w}}\right)$, in which $\theta_{\text {ref }}$ and $\theta_{\mathrm{w}}$ are the field capacity and wilting point, respectively. On the right side of the above equation, $E_{\mathrm{p}}$ is the potential evaporation calculated by a Penman-based energy balance approach that includes a stability-dependent aerodynamic resistance (Mahrt and Ek, 1984), and $\sigma_{\mathrm{f}}$ is the fraction of surface vegetation cover. The evaporation in Eqs. (2)-(4) is calculated from

$E_{\mathrm{T}}=\sigma_{\mathrm{f}} E_{\mathrm{p}} B_{\mathrm{c}}\left\lfloor 1-\left(W_{\mathrm{c}} / S\right)^{0.5}\right\rfloor$

where $B_{\mathrm{c}}$ is a function of canopy resistance, $W_{\mathrm{c}}$ the intercepted canopy water and calculated according to the budget for intercepted canopy water, and $S$ the maximum canopy capacity. This system is currently used in the soil-hydrology module of MM5. For additional details concerning each term in Eqs. (2)-(5), the reader is referred to Chen et al. (1996) and Chen and Dudhia (2001).

To obtain Eq. (5), an important assumption was made, i.e. the hydraulic diffusivity in the layer beneath the fourth layer of the model is set to zero, or equivalently, the hydraulic gradient between the model's deepest layer and the groundwater table is negligible. As a consequence, the soil water flux across the lower boundary of the model's soil column is only the gravitational percolation or subsurface runoff; no water flux into the column is allowed. This assumption may be valid for areas where groundwater table is deep and far from the lower boundary of the soil column. However, in areas of shallow groundwater, the water table may be high enough to create a substantial hydraulic gradient between the deepest soil layer and the water table, or, even extend into the model soil layers. In those areas, Eq. (5) becomes invalid.

Soil moisture variations in shallow groundwater areas behave very differently from those in areas with deep groundwater table. These differences can be seen in Fig. 2 showing comparisons of observed soil moisture at Gudmundsen and Ainsworth in the Sand Hills. Gudmundsen is at the center of the Sand Hills (Fig. 3) and has an average groundwater table at $1.5 \mathrm{~m}$ during 1989-1992 and 1.22 m during 1999-2000. Ainsworth is at the periphery of the Sand Hills and has an average groundwater table about $9 \mathrm{~m}$ below the surface. In addition, because Ainsworth's upper soil layers have high clay content (Gudmundsen's have mostly fine sand), water content in the upper layers at Ainsworth is often higher than that at Gudmundsen, particularly during the wet period from April through June. At the deeper layers, however, the soil moisture content is much smaller at Ainsworth than at Gudmundsen. The high moisture content in deep soil layers in Gudmundsen is largely attributed to the influence of groundwater. Such influence is trivial at Ainsworth because of its deep groundwater table. Lacking a groundwater source, the soil moisture content in the deep layers is smaller than in the upper layers in the wet season and larger in dry periods (Fig. 2a). In contrast, at Gudmundsen, soil moisture in deep layers is affected by groundwater, and the observed soil moisture content in those layers is always larger than in the shallow layers (Fig. 2b). The large water content in the deep soil layers maintains an upward vertical soil moisture gradient in soil and contributes to soil moisture at shallow layers and to evaporation. Clearly, the variation in soil moisture at Gudmundsen can be described accurately only when the groundwater effect is considered.

A method to include the groundwater effect on soil moisture in shallow layers and root zone is to use a non-zero hydraulic diffusivity between the deepest model soil layer and the groundwater table. 


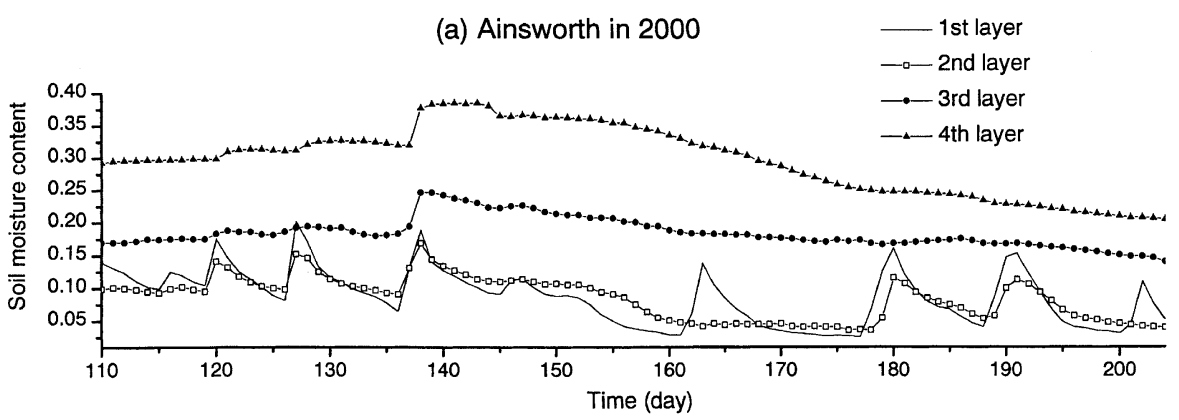

(b) Gudmundsens in 2000

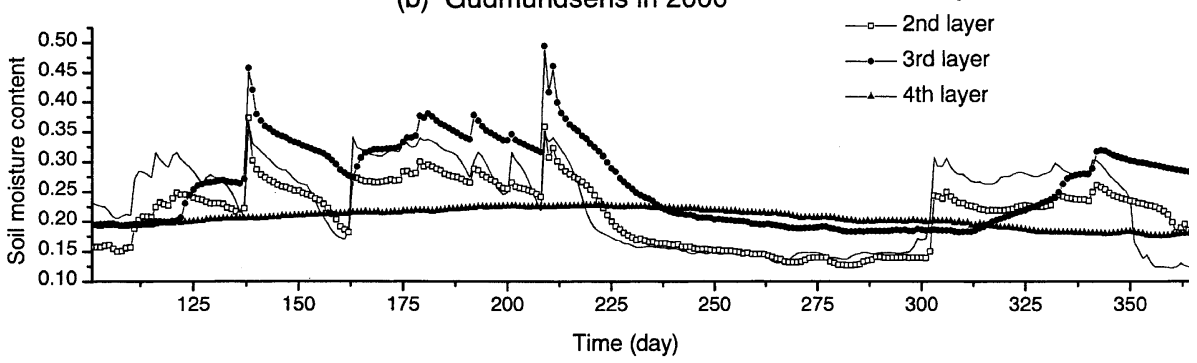

Fig. 2. Observed daily variations of soil moisture (unit: $\mathrm{m}^{3} \mathrm{~m}^{-3}$ ) at (a) Ainsworth and (b) Gudmundsen at depths, 0.10, 0.25, 0.50, and 1.0 m.

Then Eq. (5) becomes

$d_{4} \frac{\partial \theta_{4}}{\partial t}=D\left(\frac{\partial \theta}{\partial z}\right)_{3}-D\left(\frac{\partial \theta}{\partial z}\right)_{4}+K_{3}-K_{4}$

The term $D(\partial \theta / \partial z)_{4}$ is determined using the soil moisture difference between the saturated zone, which could extend into deep model layers, and the next unsaturated soil layer and the distance between groundwater table and the mid-point of the affected layer, $Z_{\mathrm{g}}$ (see Fig. 1). Eq. (6) also allows the groundwater table to vary with time.

In addition to including the groundwater effect, we also use a vertically varying saturation soil hydraulic conductivity, $K_{\mathrm{s}}$. Beven (1984) and

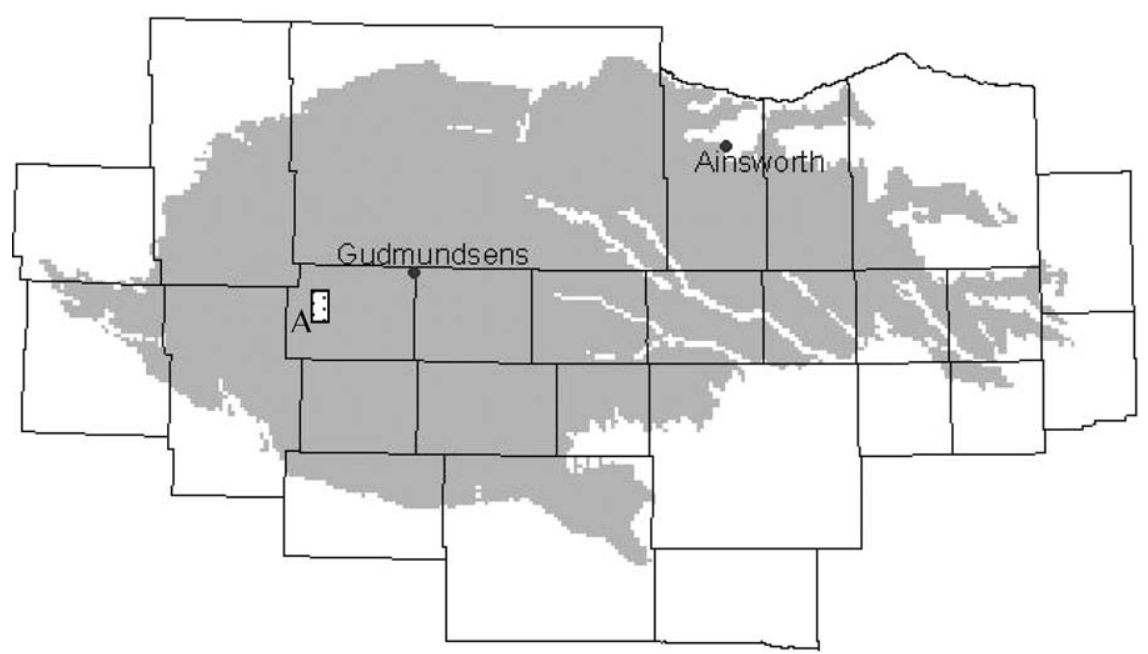

Fig. 3. The Nebraska Sand Hills and the locations of Gudmundsen and Ainsworth stations. Area $A$ is used in the regional analysis described in Section 4 . 
Elsenbeer et al. (1992) showed that in the natural environment with the presence of groundwater, hydraulic conductivity decreases exponentially with depth:

$$
K_{\mathrm{s}}(z)=K_{0} \mathrm{e}^{-f z}
$$

In Eq. (7), $K_{0}$ is the hydraulic conductivity at the surface and $f$ is the e-folding depth. This varying $K_{\mathrm{S}}$ also has been used in most TOPMODEL-based soilhydrology models (e.g. Famiglietti and Wood, 1994; Stieglitz et al., 1997; Chen and Kumar, 2002). With Eq. (7), the new model, consisting of Eqs. (1)-(4) and (6), describes exchanges of groundwater in the saturated zone and soil moisture of the unsaturated layers in the root zone.

\section{Groundwater effect on soil moisture}

\subsection{Sensitivity analysis}

To elucidate groundwater effect on soil moisture, we integrated the new model in an offline setting (uncoupled to the atmospheric model). Specifically, soil moisture variation was determined for loamy sand soil with different groundwater table depths in two hypothetical extreme weather cases. The first case consists of 3 days with continuous rain at a constant rate of $1.27 \mathrm{~mm} \mathrm{~h}^{-1}$ and no ET. The second case has three consecutive dry days with total daily ET of $6.78 \mathrm{~mm}$, which is the mean April daily evaporation at Gudmundsen (calculated using the 1998-2000 data of an automated weather station at Gudmundsen). The diurnal variation of ET is from $0.0 \mathrm{~mm} \mathrm{~h}^{-1}$ at 00:00 local time to $0.44 \mathrm{~mm} \mathrm{~h}^{-1}$ at 14:00 local time.
Soil moisture in the top $1 \mathrm{~m}$ of the unsaturated zone was determined from integration of the model over four layers with depths of $0.1,0.15,0.25$, and $0.5 \mathrm{~m}$ from top to bottom. The initial soil moisture in these four layers was set to be $0.022,0.06,0.182$, and $0.399 \mathrm{~m}^{3} \mathrm{~m}^{-3}$, respectively, again based on observations. The parameters describing the soil hydraulic properties and radiation properties of a grass cover at the site are listed in Table 1.

The groundwater effect is identified from comparisons of results from the new model to results from the original model (1)-(5), which does not consider groundwater. Fig. 4 shows the soil moisture variations in the rainy case using a constant groundwater table at the center of the fourth layer. Because of the groundwater, the fourth layer in the new model remains saturated (solid line). In the third layer, a smaller difference is observed between the results from the two models. The difference in soil moisture began to increase at the end of the first 2 days. This delay was caused by both the models' response time to initial soil moisture condition and the gradually strengthening effect of the soil moisture in the fourth layer on the third layer. In the model without groundwater, the drying in the fourth layer was large due to subsurface runoff. The drying in the fourth layer exerted a similar effect on soil moisture in the third layer. The total soil moisture in the model without groundwater is much smaller than the model with groundwater. These differences depict the groundwater effect on soil moisture in this rainy case.

In the panels of Fig. 4 we also plotted the results from a model without groundwater but using an exponentially decreasing saturation soil hydraulic conductivity $\left(K_{\mathrm{s}}\right)$. In this calculation, we used an e-folding depth of $1.65 \mathrm{~m}^{-1}$, which was estimated

Table 1

Soil and vegetation related model parameters

\begin{tabular}{llllll}
\hline Soil & $\theta_{\mathrm{s}}\left(\mathrm{m}^{3} \mathrm{~m}^{-3}\right)$ & $\Psi_{\mathrm{s}}(\mathrm{m})$ & $K_{\mathrm{s}}\left(\mathrm{m} \mathrm{s}^{-1}\right)$ & $\theta_{\mathrm{f}}\left(\mathrm{m}^{3} \mathrm{~m}^{-3}\right)$ & $\theta_{\mathrm{w}}\left(\mathrm{m}^{3} \mathrm{~m}^{-3}\right)$ \\
Loamy sand & 0.421 & 0.036 & $1.41 \times 10^{-5}$ & 0.283 & $b^{2}$ \\
& & & & & \\
Vegetation & Albedo & $Z_{0}(\mathrm{~m})$ & $R_{\mathrm{cmin}}$ & $R_{\mathrm{gl}}$ & $h_{\mathrm{s}}$ \\
Grass & 0.19 & 0.08 & 40.0 & 100.0 & 36.35 \\
\hline
\end{tabular}

$\theta_{\mathrm{s}}$, volumetric water content at saturation; $\Psi_{\mathrm{s}}$, saturation soil suction; $K_{\mathrm{s}}$, hydraulic conductivity at saturation; $\theta_{\mathrm{f}}$, field capacity; $\theta_{\mathrm{w}}$, wilting point; $b$, an exponent in the function that relates soil water potential and water content; $Z_{0}$, roughness length in meter; $R_{\mathrm{cmin}}$, minimal stomatal resistance in $\mathrm{s} \mathrm{m}^{-1} ; R_{\mathrm{gl}}$, the visible solar flux for which $F_{1}$ is about to double its minimum value; $h_{\mathrm{s}}$, a parameter used in calculating $F_{2}$. (Details of these parameters are given in Chen and Dudhia (2001)). 

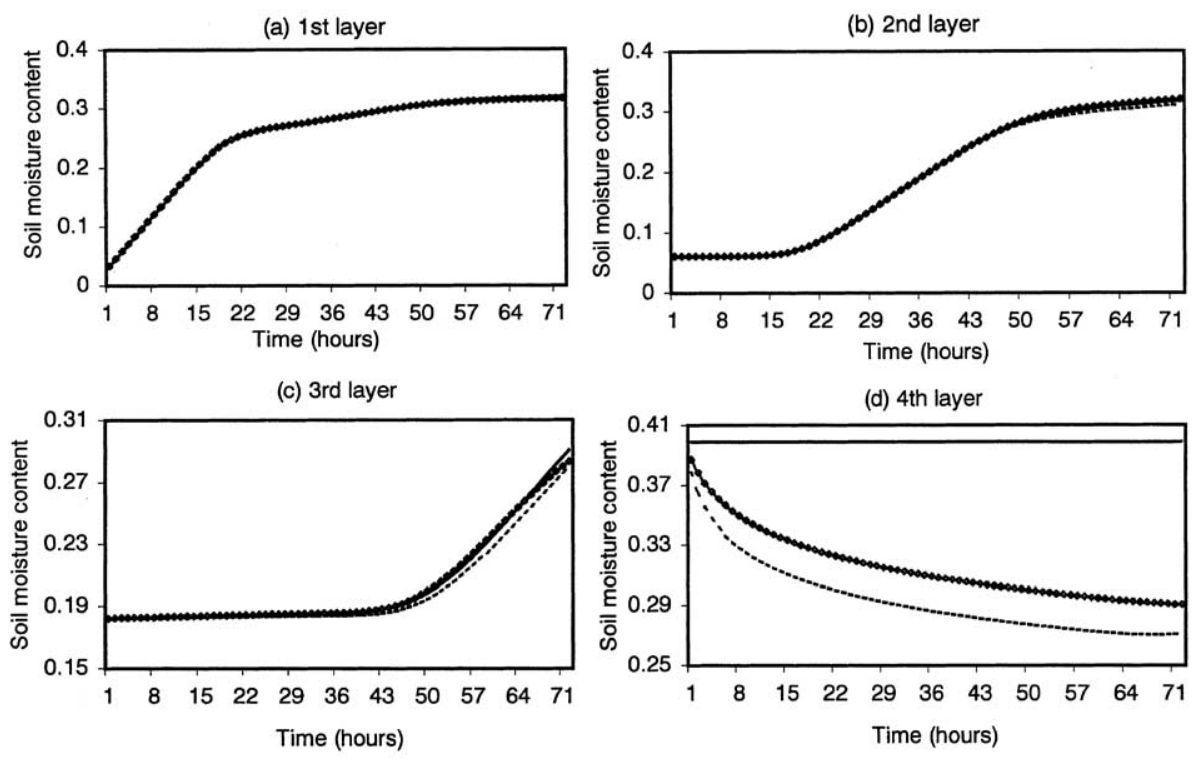

(e) Total

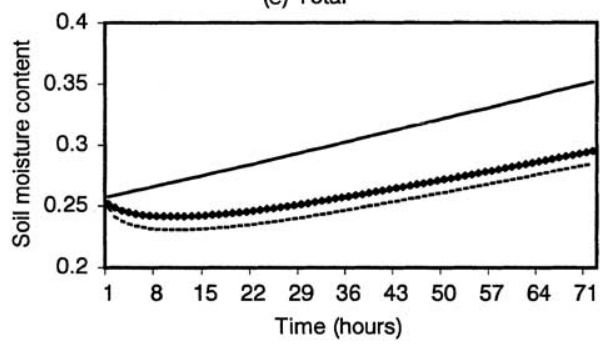

.... without groundwater influence, $\mathrm{K}=$ const

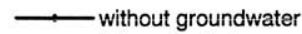
influence, $\mathrm{K}$ decrease

- with groundwater influence, $\mathrm{K}$ decrease)

Fig. 4. Temporal variations of soil moisture of different layers in three experiments.

from comparisons of model calculated soil moisture in the four layers against observations at Gudmundsen. Comparisons with the results from the original model, which uses constant $K_{\mathrm{s}}$, indicate that a $K_{\mathrm{s}}$ varying with depth can reduce the subsurface runoff (percolation) and increase soil moisture in deep layers.

With a lowered groundwater table, groundwater effect on soil moisture weakens. This effect is shown by the new model's results in Figs. 5 and 6. Fig. 5 shows that although the moisture input increases in the rainy case, the amount of soil moisture decreases when the groundwater table, $Z_{\mathrm{g}}$, increases. At the end of the three rainy days, the total soil moisture was reduced by about 19\% when the depth of the groundwater table dropped from the center of the fourth layer to $1 \mathrm{~m}$ below it. Similar effect also is shown in Fig. 6 for the dry case, wherein the groundwater has a much greater effect on soil moisture. At the end of the 3 days, the total soil moisture was reduced by $25 \%$ in response to the same change of the groundwater table. These changes in soil moisture caused by groundwater will further affect the surface evaporation and soil water exchange with the atmosphere.

\subsection{Case studies}

After showing the groundwater effect on soil moisture, we apply the new model to real cases and evaluate the magnitude and importance of groundwater effects in the Sand Hills of Nebraska. The model is validated against Gudmundsen's observations and then used to quantify the groundwater effects on soil moisture and evaporation. 


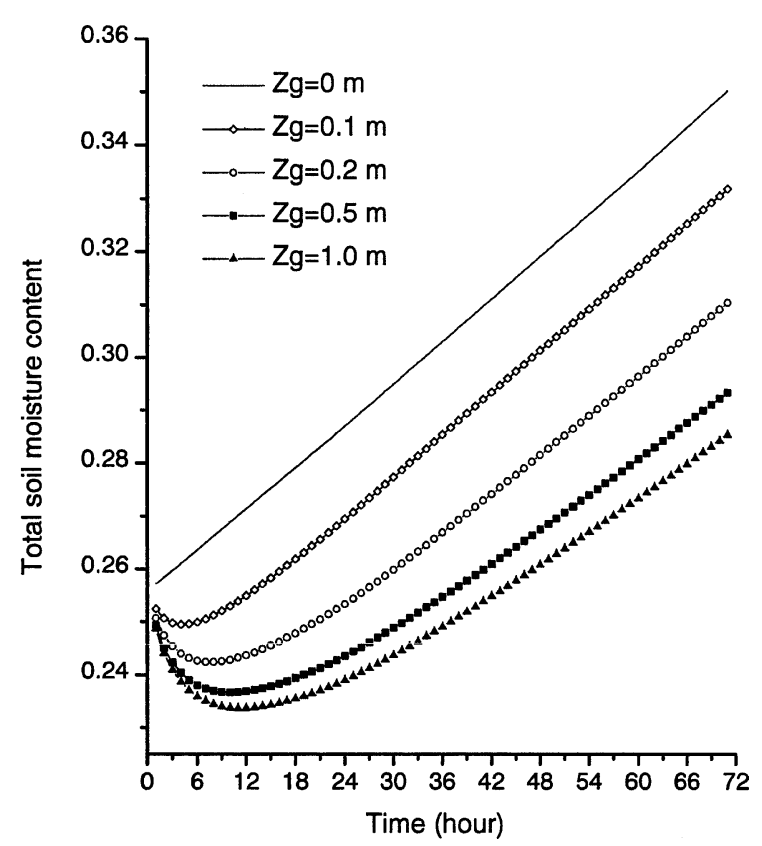

Fig. 5. Variations of total soil moisture content (unit: $\mathrm{m}^{3} \mathrm{~m}^{-3}$ ) in precipitation experiments with different groundwater table depths, $Z_{\mathrm{g}}$.

\subsubsection{Model validation}

In validating the model, we used it to describe variations of soil moisture at Gudmundsen for three periods from 1998 to 2000 when sufficient atmospheric and groundwater table data were available, and compared the model results against in situ observations of soil moisture.

The climate and weather data used to drive the model are from an automated weather station at Gudmundsen. Among the data are hourly averaged air temperature, relative humidity, wind speed and direction at $3 \mathrm{~m}$ above the surface, global solar radiation, and hourly precipitation. Soil moisture also was measured at the station at four depths, $0.10,0.25,0.50$, and $1.0 \mathrm{~m}$, which represent the probe depths of the layers $0-0.127 \mathrm{~m}\left(0-5^{\prime \prime}\right), 0.127-$ $0.381 \mathrm{~m}\left(5-15^{\prime \prime}\right), 0.381-0.762 \mathrm{~m}\left(15-30^{\prime \prime}\right), 0.762-$ $1.22 \mathrm{~m}\left(30-48^{\prime \prime}\right)$, respectively. Because continuous measurements of these atmospheric and soil moisture data were available only in the periods of May 5-November 30, 1998, April 1-August 14, 1999, and April 20-July 23, 2000, the model was validated for those three periods.

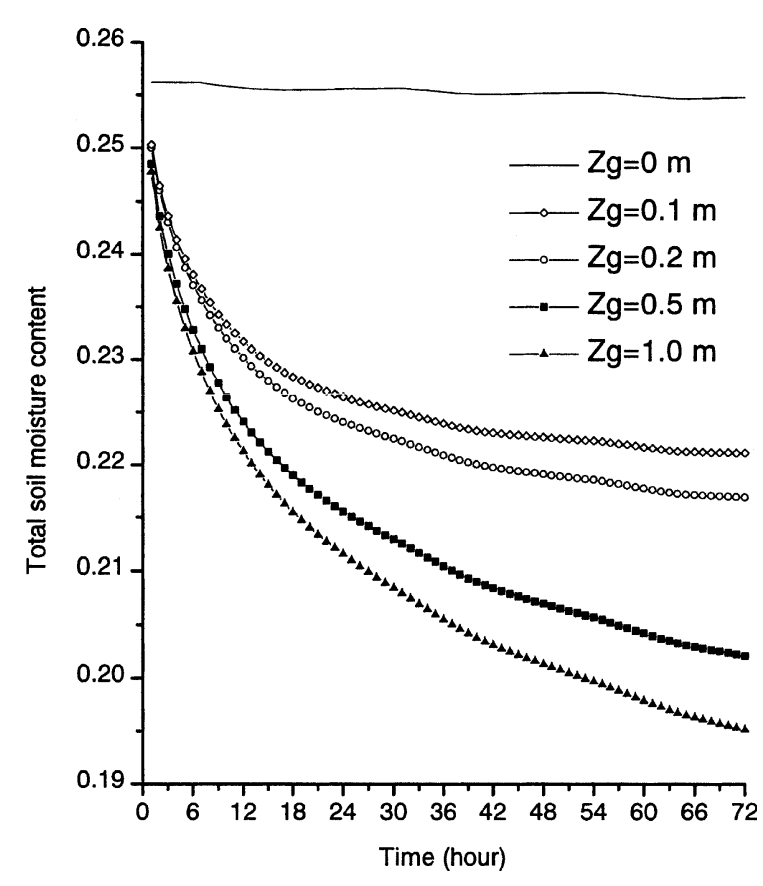

Fig. 6. Variations of total soil moisture content (unit: $\mathrm{m}^{3} \mathrm{~m}^{-3}$ ) in evaporation experiments with different groundwater table depths, $Z_{\mathrm{g}}$.

The depth to groundwater table at Gudmundsen was measured at an observation well, operated by the Nebraska Conservation and Survey Division (CSD). The observation had a monthly schedule from 1989 to 1992, but was changed after 1992 to a needs-based measurement. Because monthly observations of the groundwater table depth were not available in every month in the three validation periods, we used the following method to derive the monthly average depth to groundwater table for the months. We used the only available measurements made in April 1998, June 1999, and May 2000 as the 'anchor' points for variations of monthly groundwater table depth in each period. They are $1.07,1.31$, and $1.26 \mathrm{~m}$, respectively. For the other months in each period, the groundwater table depths were calculated using the value of the anchor month (e.g. April for the 1998 validation period) and the monthly groundwater table change rate computed from the observed mean monthly variation in 1989-1992 (Fig. 7). Additionally, because the groundwater table varies slowly and is usually considered well described by data of monthly 


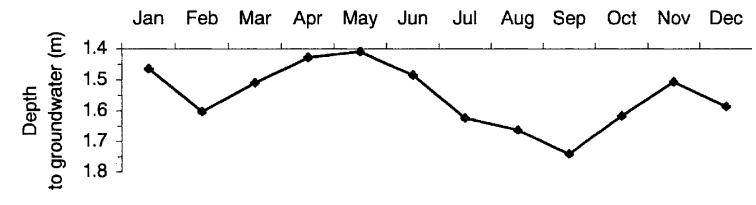

Fig. 7. Observed monthly variation of groundwater table depth (m) at Gudmundsen.

resolution (Dunne, 1978), we used a constant groundwater table depth for individual months in our calculations.

These atmospheric and groundwater table data were used to drive the new model, whose soil column was discretized into four layers from the surface to $1.22 \mathrm{~m}$ beneath it to match the probe layers of the observation. The model layers from top to bottom were $0.127,0.253,0.38$, and $0.46 \mathrm{~m}$, respectively. Model initial conditions were specified using the observations taken at the beginning of each validation period. Other parameters used in model validations included those describing the properties of loamy sand soil and grass cover at Gudmundsen. Values of those parameters are the same as those in Table 1. A vertically varying $K_{\mathrm{s}}$ was used with a calibrated e-folding depth $f=1.65 \mathrm{~m}^{-1}$.

Model results for the three periods are shown in Figs. 8-10. Also plotted in these figures are, for comparison purposes, observed soil moisture and the soil moisture calculated from the model (1)-(5) without the groundwater. Comparisons of the results from the two models and with the observations indicate that groundwater has minor influence on soil moisture in the first and second layers, which comprise the top $0.38 \mathrm{~m}$ in the soil column. (The difference between the modeled and observed soil moisture in the top two layers is sometimes large, resulting from considerable variations of the soil moisture caused by both precipitation and evaporation.) Groundwater effect on soil moisture is however quite substantial in the third and fourth layers from 0.38 to $1.22 \mathrm{~m}$. Without the groundwater, the calculated soil moisture in those deep layers is much lower. This unrealistic dryness, as compared to the observation, is particularly severe in spring and early summer (April to June) when the groundwater table is highest in the year and, hence, the groundwater effect on soil moisture is most significant. The dryness also is severe in wet periods when the subsurface runoff drains the deep layers more effectively than in dry periods with less soil water available for depletion. With the groundwater, the calculated soil moisture in the deep layers is close to the observed and yields total soil moisture in the soil column nearly identical to the observed (Fig. 8e). These comparisons demonstrate that the groundwater is essential to maintaining realistic soil moisture content in deep soil layers and soil moisture profile. They indicate that the groundwater and its seasonal variation play an important role in soil moisture and its profile variations and, thus, should be taken into account in soil hydrology models in order to correctly describe soil moisture and related surface hydrological processes, especially in areas where the groundwater table is high.

\subsubsection{Groundwater effects on soil moisture and evaporation}

After verifying that the improved model captured the soil moisture variation at Gudmundsen, we used the model data to evaluate the groundwater influence on the soil water budget in the root zone. The results are summarized in Table 2. Among these budget components are total evapotranspiration, $E$, surface runoff, $R$, drainage to groundwater, $R_{\mathrm{g}}\left(=K_{4}\right)$ in Eq. (6), and groundwater loss, LG, discussed below. $E$ is the sum of the direct evaporation from the top layer, $E_{\mathrm{dir}}$, evaporation of intercepted rainwater on canopy, $E_{\mathrm{c}}$, and transpiration via canopy and roots in the soil layers, $E_{\mathrm{t}}$. Details of parameterizations for these components were described in Section 2 and in Chen et al. (1996) and Chen and Dudhia (2001).

Table 2 shows that because of the moisture supply from the groundwater the average $E$ from the model with groundwater is greater by 21,8 , and $7 \%$ for each of the three periods, respectively, than that from the model without groundwater. The surface runoff, $R$, is calculated from $R=P_{\mathrm{d}}-I_{\max }$, where $I_{\max }$ is the maximum infiltration. Because of the high infiltration rate in the Sand Hills, $P_{\mathrm{d}}$ seldom exceeds $I_{\max }$ so $R$ is minimal. In calculation, the value of $I_{\max }$ was set equal to the hydraulic conductivity at saturation (Table 1).

The total groundwater loss in form of supply to soil moisture (LG) depends on the soil type, precipitation, potential evaporation, and depth of the groundwater table. For a fixed soil type, the loss can be computed 

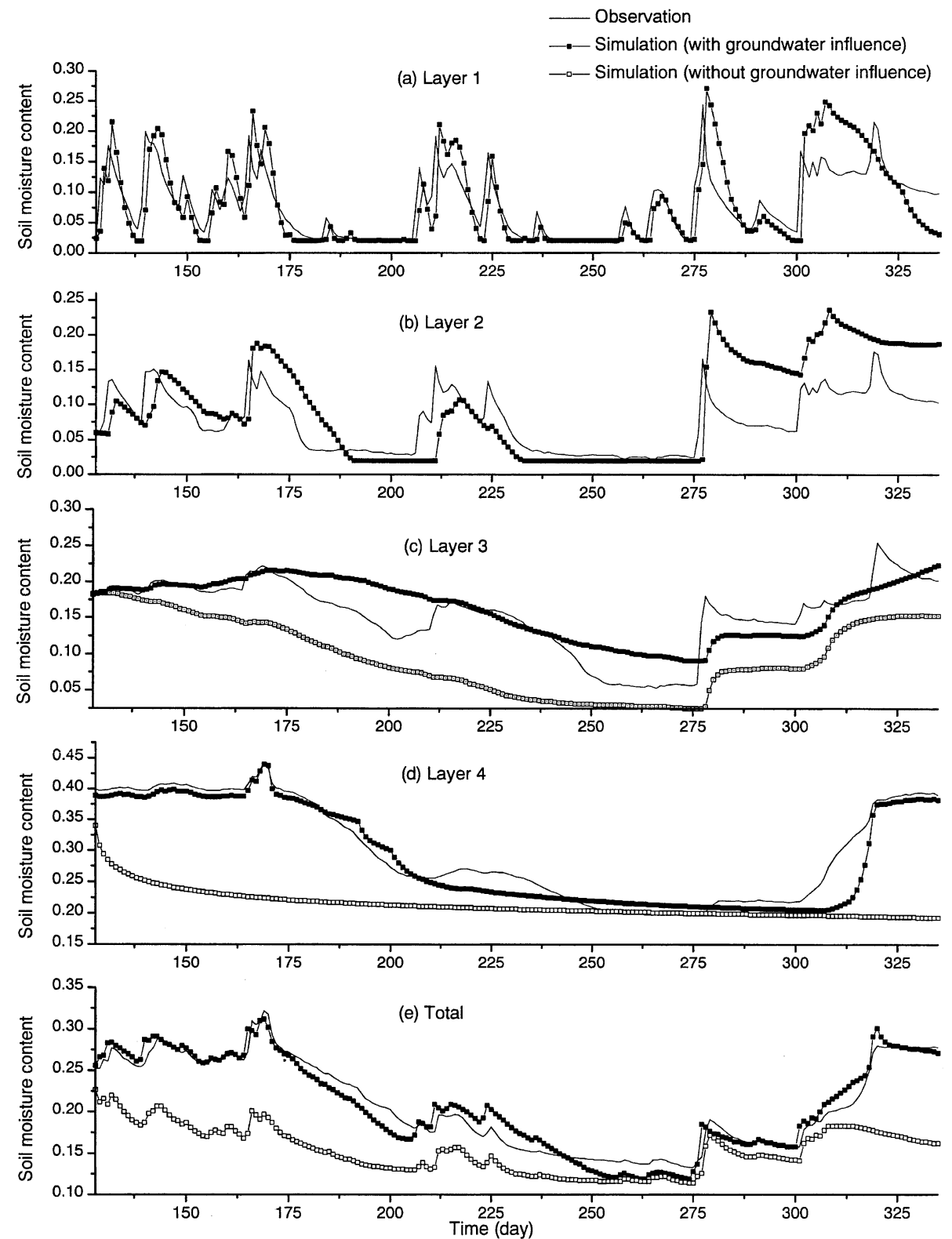

Fig. 8. Simulated and observed variations of soil moisture (unit: $\mathrm{m}^{3} \mathrm{~m}^{-3}$ ) from May 5 through November 30,1998 .

from:

$\mathrm{LG}=-K(\Psi)\left(\frac{\partial \Psi}{\partial z}\right)_{4}=-D\left(\frac{\partial \theta}{\partial z}\right)_{4}$

The total loss in each of the periods calculated using Eq. (8) is shown in Table 2. Between the two periods in 1998 and 2000, the average depth of groundwater table is about the same. However, more precipitation in 1998 corresponds to larger $E$ and more LG. Our calculations further show that $58 \%$ of the $E$ in 1998 was from the groundwater whereas only $32 \%$ was from the groundwater in 2000. On the other hand, between the two periods in 1999 and 2000, the total rainfall is similar but the difference in the depth to 

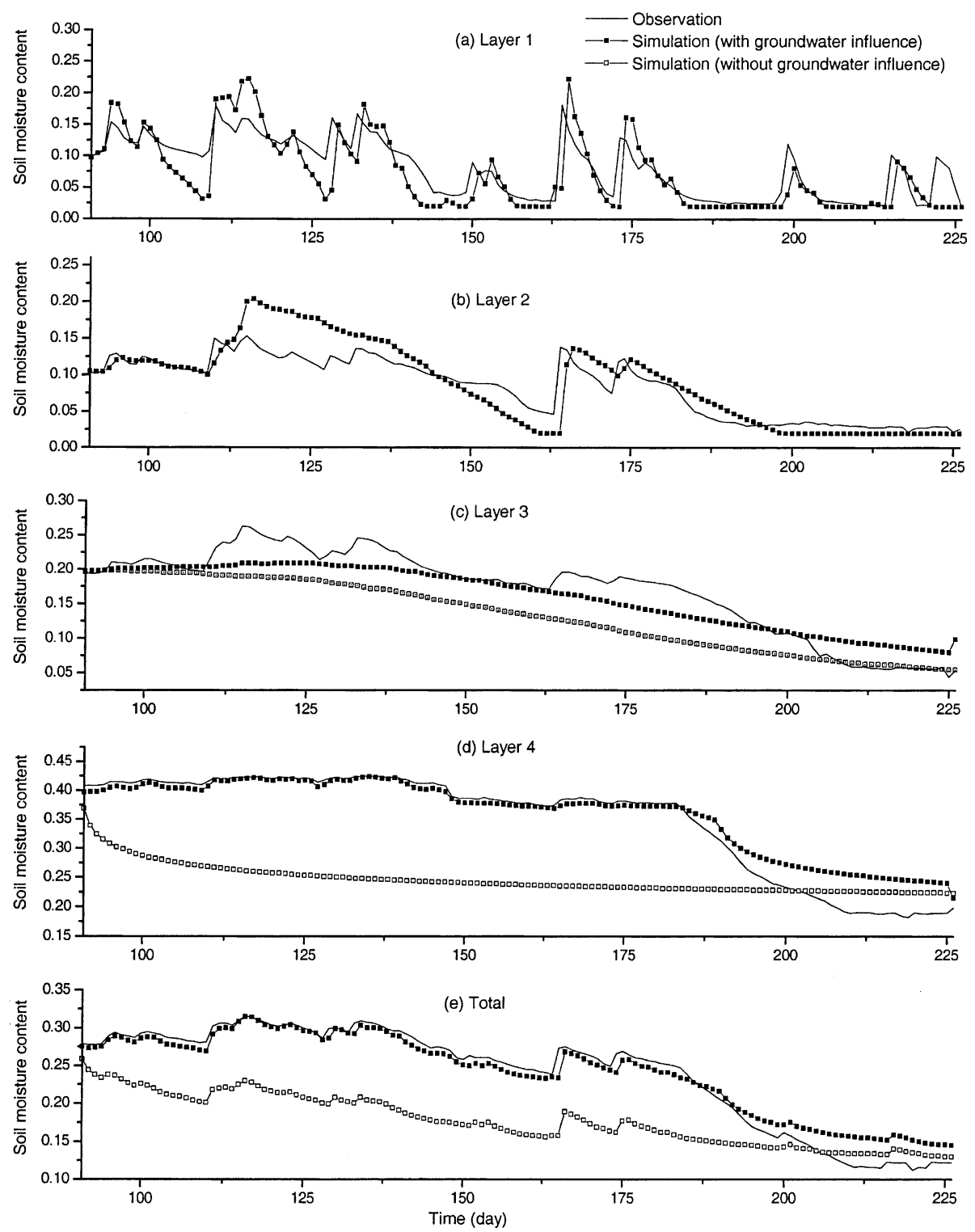

Fig. 9. Simulated and observed variations of soil moisture (unit: $\mathrm{m}^{3} \mathrm{~m}^{-3}$ ) from April 1 through August 14, 1999.

the groundwater table is large. This difference has resulted in a large difference in LG. Specifically, when the groundwater table sank to $1.32 \mathrm{~m}$ in 1999 only $15 \%$ of $E$ was from the groundwater vs. $32 \%$ in 2000 with a higher water table at $1.17 \mathrm{~m}$.

Precipitation recharge to the groundwater, $R_{\mathrm{g}}$, was calculated as the gravitational percolation through the soil column, $K_{4}$ in Eq. (6). The results in Table 2 show that this percolation consumes
$18-30 \%$ of the total precipitation at Gudmundsen. This percentage range of rainfall recharge to groundwater is comparable to the annual recharge amount of $20-30 \%$ of annual precipitation in the Sand Hills (Nebraska Natural Resources Commission, 1986). Apparently, this large recharge of rainfall has played a key role in maintaining the rich groundwater in the Nebraska Sand Hills and adjacent semiarid regions. This recharge would be 

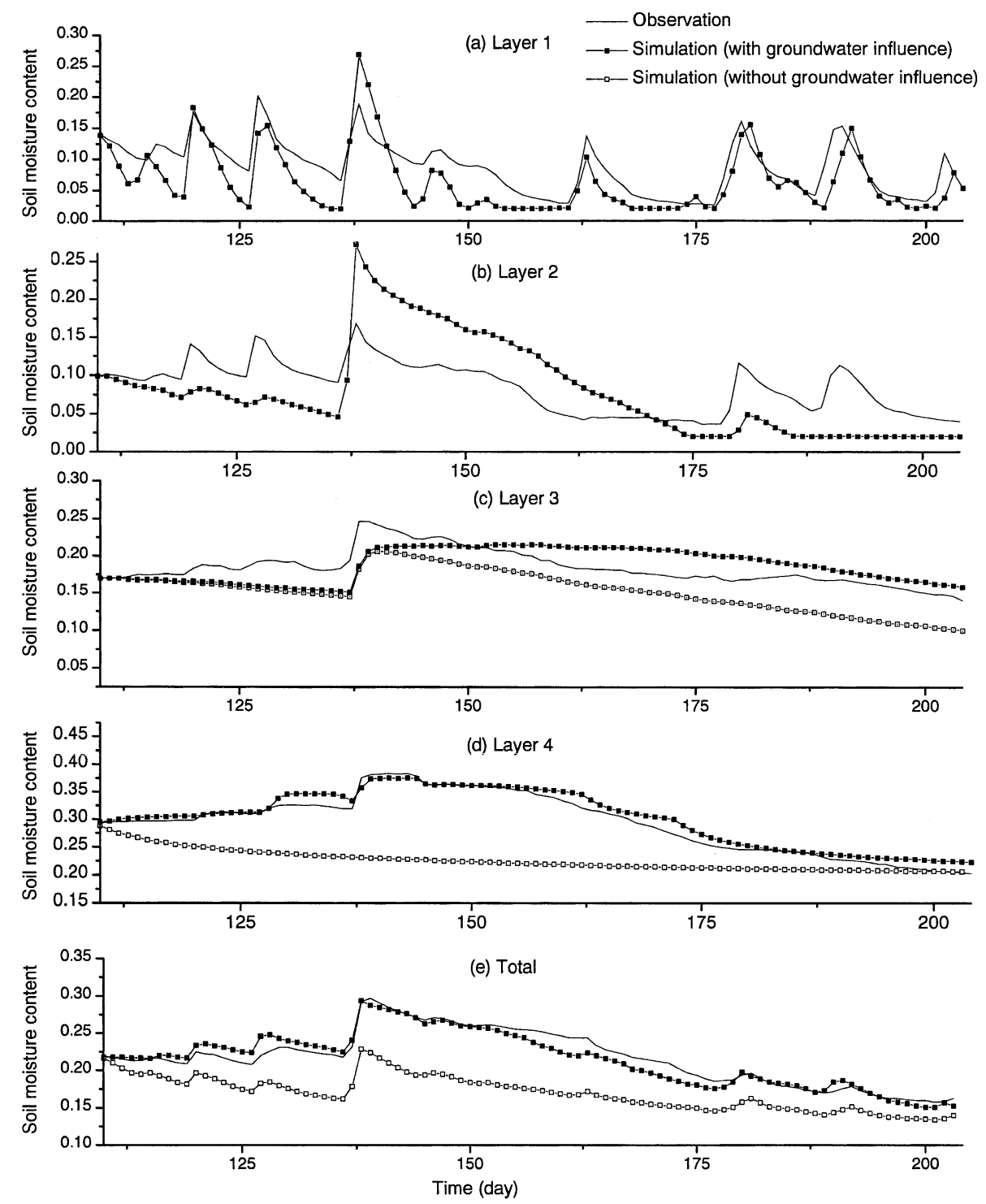

Fig. 10. Simulated and observed variations of soil moisture (unit: $\mathrm{m}^{3} \mathrm{~m}^{-3}$ ) from April 20 through July $23,2000$.

significantly underestimated in the model without the groundwater. An explanation for the difference in this recharge between the two models is that the root zone is drier in the model without groundwater (see the soil moisture values in Table 2) because of lack of groundwater transfer to that zone. More infiltrated water is kept in the zone to charge the soil water capacity and support evaporation and transpiration. In the model with groundwater, the soil is wetter (see Table 2) because of groundwater transfer and, hence, more infiltrated water is passing through that zone to charge the groundwater.

\section{Groundwater effects on regional soil moisture and evaporation}

Because of the groundwater effects on soil moisture and the local water cycle, spatial variations 
Table 2

Simulated and observed hydrological components

\begin{tabular}{|c|c|c|c|c|c|c|c|c|c|c|}
\hline \multirow[t]{2}{*}{ Simulation periods } & \multirow[t]{2}{*}{ Classification } & \multirow[t]{2}{*}{$P_{\mathrm{d}}(\mathrm{mm})$} & \multirow[t]{2}{*}{$R(\mathrm{~mm})$} & \multirow[t]{2}{*}{$E(\mathrm{~mm})$} & \multirow[t]{2}{*}{$R_{\mathrm{g}}(\mathrm{mm})$} & \multirow[t]{2}{*}{$\mathrm{LG}(\mathrm{mm})$} & \multicolumn{3}{|c|}{ Soil moisture $\left(\mathrm{m}^{3} \mathrm{~m}^{-3}\right)$} & \multirow[t]{2}{*}{$D(\mathrm{~m})$} \\
\hline & & & & & & & Starting & Ending & Mean & \\
\hline \multirow[t]{3}{*}{1998 (May 5-November 30) } & No groundwater & 404 & 0.69 & 468 & 4.80 & & 0.251 & 0.162 & 0.154 & 1.16 \\
\hline & With groundwater & 404 & 0.69 & 588 & 129.7 & 340.2 & 0.251 & 0.271 & 0.209 & 1.16 \\
\hline & Observation & 404 & & & & & 0.251 & 0.278 & 0.209 & 1.16 \\
\hline \multirow[t]{3}{*}{1999 (April 1-August 14) } & No groundwater & 274 & 0.00 & 384 & 7.68 & & 0.270 & 0.140 & 0.178 & 1.32 \\
\hline & With groundwater & 274 & 0.00 & 416 & 48.24 & 61.05 & 0.270 & 0.135 & 0.241 & 1.32 \\
\hline & Observation & 274 & & & & & 0.270 & 0.145 & 0.240 & 1.32 \\
\hline \multirow[t]{3}{*}{2000 (April 20-July 23) } & No groundwater & 245 & 4.68 & 343 & 4.51 & & 0.218 & 0.147 & 0.170 & 1.17 \\
\hline & With groundwater & 245 & 4.68 & 370 & 48.15 & 117.9 & 0.218 & 0.168 & 0.217 & 1.17 \\
\hline & Observation & 245 & & & & & 0.218 & 0.172 & 0.215 & 1.17 \\
\hline
\end{tabular}

$D$ is the mean depth to groundwater.

in the groundwater table depth can result in spatial heterogeneity in soil moisture and, subsequently, surface moisture flux across a region. It is important to evaluate the significance of such heterogeneity and its effect on regional evaporation. We examined the regional soil moisture variations and compared the regional surface moisture flux calculated from the two models in a $72 \mathrm{~km}^{2}$ Sand Hills area (area $A$ in Fig. 3). Because of data limitations this evaluation is only for 1998. The observed 1998 annual average groundwater table in the area was obtained from spatial interpolation of nearly 700 observation wells in the Sand Hills (six of them are in area $A$, data from the Nebraska CSD: http://csd.unl.edu/csd/metadata/ topog.html). The average depth of the groundwater table in the study area was $13 \mathrm{~m}$, and the depth varied from $0 \mathrm{~m}$ in wet meadows of interdunal valleys to $57 \mathrm{~m}$ under large sand dunes. Details of the observed spatial distribution of groundwater table depth are shown in Fig. 11, in which the light shading indicates shallow groundwater table in meadows and wetlands, and the dark shading indicates dunes with a deep water table.

In simulating spatial variations of the soil moisture, we divided the area into grids, and each grid has a size $300 \mathrm{~m} \times 300 \mathrm{~m}$. The same sandy soil and grass cover parameters were used at each grid cell. At its center, the observed groundwater table, rainfall and other atmospheric variables observed at Gudmundsen were used to calculate soil moisture, evaporation, and transpiration using both the two models with and without the groundwater. Model simulations started on May 7, 1998 using the observation taken at 01:00 local time as the initial condition and ended at 00:00 local time on September 30, 1998.

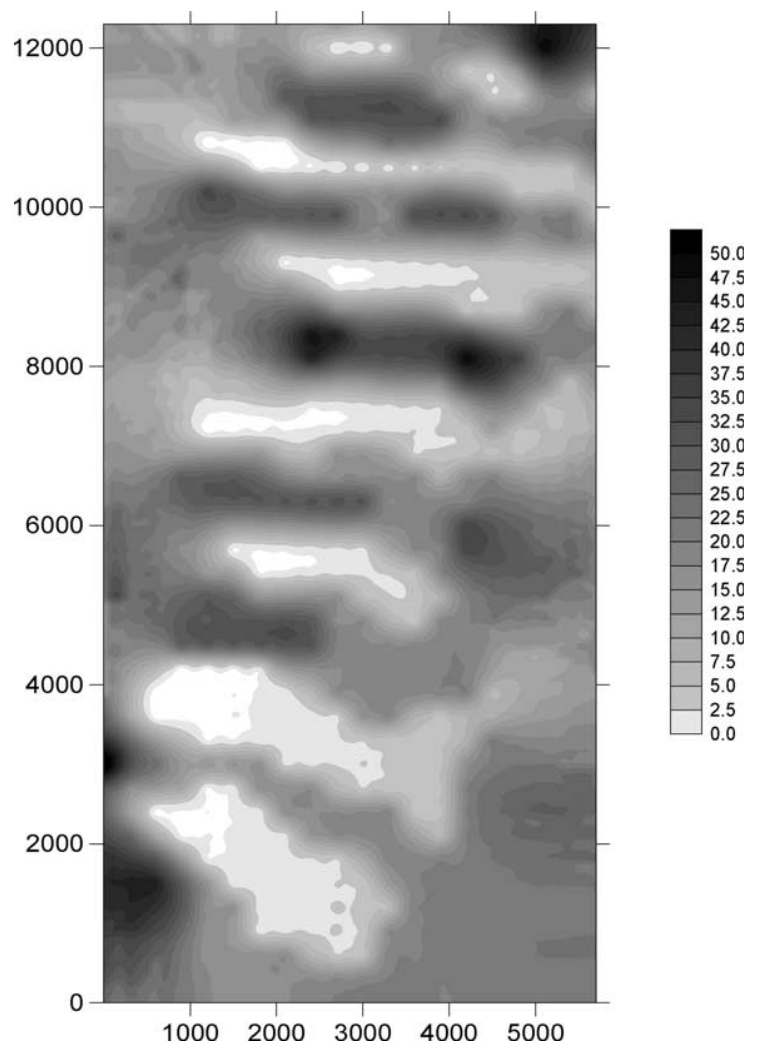

Fig. 11. Observed spatial variation of groundwater table depth $(\mathrm{m})$. Scales along the abscissa and ordinate are in meters from the southwest corner of the region. 
Because the soil type and landcover are the same at all the grid cells, the model without groundwater produced uniform soil moisture and surface evaporation across the entire area. In contrast, the model with the groundwater described considerable spatial heterogeneity of these variables. For example, Fig. 12 shows the total soil moisture content simulated by the model with groundwater in a wet condition on June 14, 1998, after a rain event, and Fig. 13 shows the soil moisture in a dry condition on September 13, 1998, after 19 consecutive dry days. In both results, the interdunal valleys are rich in soil moisture, and the moisture content decreases away from the valleys following changes in the groundwater table, showing the groundwater effect on the soil moisture. With the capacity to represent these spatial variations in soil moisture and their contribution to surface moisture flux, the model with groundwater gives a very different area averaged $E$.

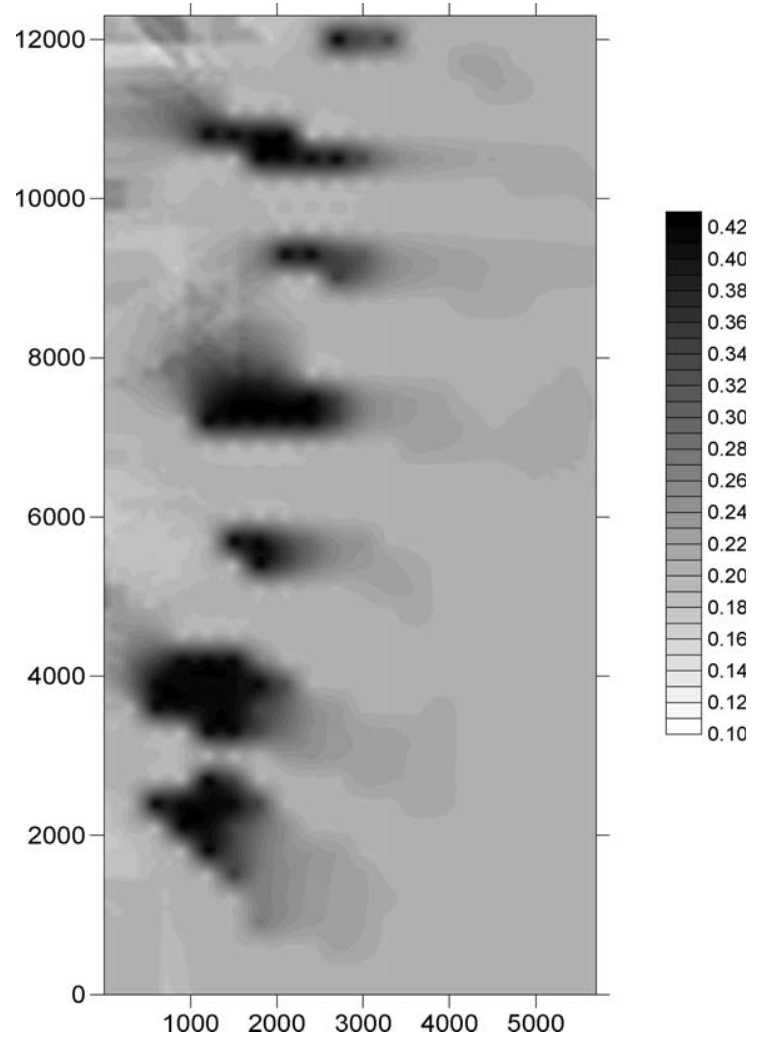

Fig. 12. Simulated daily soil moisture distribution on June 14, 1998 after a rain event.

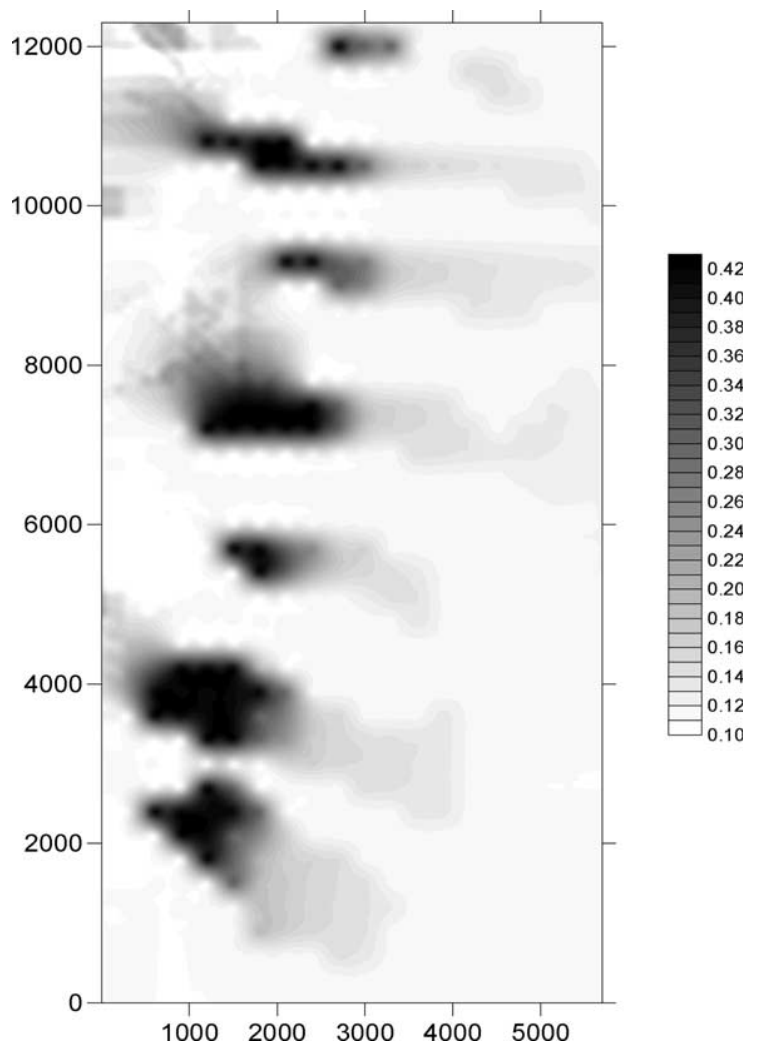

Fig. 13. Simulated daily soil moisture distribution on September 13, 1998 after 19 consecutive dry days.

For instance, on June 14, 1998, the observed average potential evaporation was $0.225 \mathrm{~mm} \mathrm{~h}^{-1}$; the averaged $E$ calculated by the model with groundwater is $0.182 \mathrm{~mm} \mathrm{~h}^{-1}$ whereas it is only $0.153 \mathrm{~mm} \mathrm{~h}^{-1}$ from the model without groundwater. This difference is more significant in dry periods. On September 13, 1998, the observed potential evaporation was $0.272 \mathrm{~mm} \mathrm{~h}^{-1}$ and the averaged $E$ from the model with groundwater is $0.0735 \mathrm{~mm} \mathrm{~h}^{-1}$, which is more than double of $0.0318 \mathrm{~mm} \mathrm{~h}^{-1}$ from the model without groundwater. This difference shows the effect of spatial variation in groundwater table on regional soil moisture and surface evaporation.

\section{Summary and concluding remarks}

Water flow in the root zone is predominantly vertical and can be described as one-dimensional in 
calculating soil moisture. Usually, this one-dimensional flow is downward, driven by both the gravitational force and a downward gradient of soil moisture. This downward movement, along with moisture depletion processes (e.g. evaporation and transpiration), has been accounted for in LSM that are used in both GCM and regional atmospheric models. In addition to precipitation, the other source of soil moisture in the root zone is the groundwater. Indeed, the effect of groundwater on soil moisture in the root zone, and hence surface evaporation, is dependent on the groundwater table depth. The effect can be significant in areas where the groundwater table is near the surface. Such areas include wetlands, lowlands in river basins, and areas similar to the interdunal valleys in the Sand Hills of Nebraska. Because of the effect of groundwater, the vertical gradient of the soil moisture content is upward in those areas, creating a unique soil hydrological environment. Spatial variations of soil moisture created by the heterogeneity of the groundwater table in those areas can add an extra spatial variability of the surface water fluxes to impact both local and region atmospheric moisture distribution. Thus, correctly representing this spatial variability associated with groundwater is important not only for improving atmospheric models to accurately describe the hydrological processes in atmosphere but also for improving our understanding of climate processes related to and influenced by the groundwater variations.

This study introduced a method to describe the groundwater effect in land surface models which can be used in regional as well as global atmospheric models. After including this method in a revised soil-hydrology model of the Penn State-NCAR MM5, we used the new model and demonstrated the groundwater effects on soil moisture and surface evaporation, using the Nebraska Sand Hills as an example. Comparisons of the results from the new model with groundwater and the original one without groundwater showed that the new model described root zone moisture content and its variation much more accurately than the model without the groundwater. Our analyses also showed that in the top $1 \mathrm{~m}$ of the soil, the total soil moisture calculated using the model with groundwater could be as much as $21 \%$ more than that in the model without the groundwater. More soil moisture in the root zone resulted in increased total evaporation. The average surface evaporation was $7-21 \%$ higher when the groundwater effect was considered, closer to the observed value. Extended calculations of a small area of $5.8 \times 12.4 \mathrm{~km}^{2}$ near Gudmundsen in the Sand Hills yielded results illustrating that the spatial heterogeneity of the groundwater table can not only create an additional spatial variations at a magnitude similar to that by landcover and topography variations, but also describe an area average evaporation nearly doubled the amount from a model without groundwater.

By showing the strong influences of groundwater on soil moisture and surface evaporation, this study encourages that the method described in Section 3 be used in LSM to account for the groundwater effects in hydrological processes in both soils and atmosphere. Although regions with groundwater table depth high enough to have significant effects on soil moisture and surface evaporation is a small fraction in hemispheric and global land, those regions can be a substantial part of model domains in regional and mesoscale models. These models have often been used in studying regional land process effects on severe storm development, such as the Sand Hills effect on severe storm and tornado development in Nebraska and the storm and flood development in southeastern United States (e.g. the 1993 flood case studies) where groundwater table also is high. Because the surface hydrological processes have played an essential role particularly in enhancing storms, the groundwater and its spatial variation could be important in development of those processes. The influence of the groundwater has been neglected in the existing studies, however, applying LSM without groundwater and should be included in future studies.

\section{Acknowledgements}

The authors wish to thank Drs X.H. Chen, C. Rowe, and M. Anderson for useful discussions during this work, and Dr K. Hubbard of the High Plains Regional Climate Center (HPRCC) for helpful discussions on the HPRCC data used in this study. Thanks also go to the two anonymous reviewers whose comments helped improve the clarity of this manuscript. 
This work was supported by NOAA contract NA06GP0226 through the University of NebraskaLincoln and by USDA Cooperative Research Project NEB-40-008.

\section{References}

Acs, F., 1994. A coupled soil-vegetation scheme: description, parameters, validation, and sensitivity studies. J. Appl. Meteorol. 33, 268-284.

Bentall, R., 1998. In: Bleed, A., Flowerday, C. (Eds.), An Atlas of the Sand Hills, Resource Atlas, No. 5a, Conservation and Survey Division, University of Nebraska, Lincoln, NE, pp. 93-114.

Beven, K.J., 1984. Infiltration into a class of vertically nonuniform soils. Hydrol. Sci. J. 29, 425-434.

Beven, K.J., Kirkby, M.J., 1979. A physically based, variable contributing area model of basin hydrology. Hydrol. Sci. Bull. 24, 43-69.

Bleed, A., 1998. In: Bleed, A., Flowerday, C. (Eds.), An Atlas of the Sand Hills, Resource Atlas, No. 5a, Conservation and Survey Division, University of Nebraska, Lincoln, NE, pp. 67-92.

Chen, F., Dudhia, J., 2001. Coupling an advanced land surfacehydrology model with the Penn State-NCAR MM5 modeling system. Part I: Model implementation and sensitivity. Mon. Weath. Rev. 129, 569-585.

Chen, J., Kumar, P., 2002. Role of terrestrial hydrologic memory in modulating ENSO impacts in North America. J. Climate 15, 3569-3585.

Chen, F., Mitchell, K., Xue, Y., Pan, H., Koren, V., Duan, Q.Y., Ek, M., Betts, A., 1996. Modeling of land-surface evaporation by four schemes and comparison with FIFE observations. J. Geophys. Res. 101, 7251-7268.

Cosby, B.J., Hornberger, G.M., Clapp, R.B., Ginn, T.R., 1984. A statistical exploration of the relationships of soil moisture characteristics to the physical proprieties of soil. Water Resour. Res. 20, 682-690.

Dickinson, R.E., 1984. Modelling evapotranspiration for three dimensional global climate models. In: Hansen, J.E., Takahashi, T. (Eds.), Climate Processes and Climate Sensitivity, Geophys. Monogr. Ser., Vol. 29. AGU, Washington, DC, pp. 58-72.

Dickinson, R.E., Henderson-Sellers, A., Kennedy, P.J., Wilson, M.F., 1986. Biosphere-atmosphere transfer scheme (BATS) for the NCAR community climate model, NCAR Tech. Note TN$275+$ STR, 69 pp., Boulder, CO.

Dunne, T., 1978. Field studies of hillslope flow processes. In: Kirkby, M.J., (Ed.), Hillslope Hydrology, Wiley, Chichester, pp. 227-293.

Elsenbeer, H., Cassel, K., Castro, J., 1992. Spatial analysis of soil hydraulic conductivity in a tropical rain forest catchment. Water Resour. Res. 28, 3201-3214.

Entekhabi, D., Eagleson, P.S., 1989. Land surface hydrology parameterization for atmospheric general circulation models including subgrid scale spatial variability. J. Climate 2, 816-831.

Famiglietti, J.S., Wood, E.F., 1990. Evapotranspiration and runoff from large land areas: land surface hydrology for atmospheric general circulation models. In: Wood, E.F., (Ed.), Land Surface-Atmospheric Interactions for Climate Models: Observation, Models, and Analyses, Kluwer, The Hague.

Famiglietti, J.S., Wood, E.F., 1994. Multiscale modeling of spatially variable water and energy balance processes. Water Resour. Res. 30, 3601-3678.

Koster, R.D., Suarez, M.J., Ducharne, A., Stieglitz, M., Kumar, P., 2000. A catchment-based approach to modeling land surface processes in a general circulation model. 1. Model structure. J. Geophys. Res. 105, 24809-24822.

Mahfouf, J.F., Noilhan, J., 1991. Comparative study of various formation from bare soil using in situ data. J. Appl. Meteorol. 30, 1354-1365.

Mahrt, L., Ek, M., 1984. The influence of atmospheric stability on potential evaporation. J. Climate 8, 2039-2057.

Manabe, S., 1969. Climate and the ocean circulation. I. The atmospheric circulation and the hydrology of the Earth's surface. Mon. Weath. Rev. 97, 739-774.

Nebraska Natural Resources Commission, 1986. Policy issue study on integrated management of surface water and groundwater. State Water Planning and Review Process, 45 pp.

Ookouchi, Y., Segal, M., Kessler, R.C., Pielke, R.A., 1984. Evaluation of soil moisture effects on the generation and modification of mesoscale circulations. Mon. Weath. Rev. 112, 2281-2291.

Pan, H.L., Mahrt, L., 1987. Interaction between soil hydrology and boundary-layer development. Boundary-Layer Meteorol. 38, $185-201$.

Pielke, R.A. Sr., Avissar, R., 1990. Influence of landscape structure on local and regional climate. Landscape Ecol. 4, 133-155.

Pielke, R.A. Sr., Dalu, G., Snook, J.S., Lee, T.J., Kittel, T.G.F., 1991. Nonlinear influence of mescoscale landuse on weather and climate. J. Climate 4, 1053-1069.

Schaake, J.C., Koren, V.I., Duan, Q.Y., Mitchell, K., Chen, F., 1996. Simple water balance model for estimating runoff at different spatial and temporal scales. J. Geophys. Res. 101, 7461-7475.

Sellers, P.J., Mintz, Y., Sud, Y.C., Dalcher, A., 1986. A simple biosphere model $(\mathrm{SiB})$ for use within general circulation models. J. Atmos. Sci. 43, 505-531.

Stieglitz, M., Rind, D., Famiglietti, J.S., Rosenzweig, C., 1997. An efficient approach to modeling the topographic control of surface hydrology for regional and global climate modeling. J. Climate 10, 118-137.

Wood, E.F., Lettenmaier, D.P., Zartarian, V.G., 1992. A landsurface hydrology parameterization with subgrid variability for general circulation models. J. Geophys. Res. 97, 2717-2728.

Xue, Y., Sellers, P.J., Kinter, J.L., Shukla, J., 1991. A simplified biosphere model for global climate studies. J. Climate 4, 346-364. 